\title{
A PERTINÊCIA DA UTILIZAÇÃO DA ARBITRAGEM PELA ADMINISTRAÇÃO PÚBLICA: UMA ANÁLISE DOS PRINCÍPIOS DA ADMINISTRAÇÃO E DOS IMPACTOS ECONÔMICOS FINANCEIROS
}

\author{
THE RELEVANCE OF THE USE OF ARBITRATION BY THE PUBLIC \\ ADMINISTRATION: AN ANALYSIS OF ADMINISTRATION PRINCIPLES AND \\ ECONOMICAL AND FINANCIAL IMPACTS
}

\author{
${ }^{1}$ Mariana de Souza Saraiva \\ ${ }^{2}$ Danielle Caroline Silva
}

\section{RESUMO}

Este estudo teve como objetivo analisar a pertinência da utilização da arbitragem pela Administração Pública por meio do estudo dos princípios administrativos, bem como dos impactos econômicos financeiros frente à utilização do instituto. Para tanto, analisou-se a arbitrabilidade objetiva e subjetiva do Estado; realizou-se a análise do instituto frente aos princípios de Direito Administrativo; e fez-se a análise das repercussões econômicas advindas em virtude da inserção da cláusula compromissória nos contratos celebrados pelo Estado. Ao final concluiu-se pela pertinência e vantagens da utilização da arbitragem pela Administração Pública brasileira.

Palavras-chave: Arbitragem, Administração pública, Princípios de direito administrativo, Direito e economia

\begin{abstract}
The aim of this study was to analyze the relevance of the use of arbitration by the Public Administration by means of administrative principles study, as well as of the financialeconomic impacts against the institute's utilization. It was analyzed the objective and subjective arbitrability of the State; an institute's analysis against the principles of the Administrative Law; and an analysis of the economic repercussion due to the insertion of the arbitration clause contained in contracts made by State. At the end, it was concluded by the relevance and benefits of the use of arbitration by the Brazilian Public Administration.
\end{abstract}

Keywords: Arbitration, Public administration, Administrative law principles, Law and economics

\footnotetext{
${ }^{1}$ Mestranda pela Pontifícia Universidade Católica de Minas Gerais - PUC/MG, Minas Gerais (Brasil). Professora de Direito Empresarial e Estágio Supervisionado da Pontifícia Universidade Católica de Minas Gerais - PUC/MG, Minas Gerais (Brasil). E-mail: saraivamariana@ hotmail.com

${ }^{2}$ Mestranda pela Pontifícia Universidade Católica de Minas Gerais - PUC/MG, Minas Gerais (Brasil). E-mail: dcs_adv@yahoo.com.br
} 


\section{INTRODUÇÃO}

A arbitragem é um meio privado e extrajudicial de solução de controvérsias heterocompositivo. Por meio deste instituto, pessoas capazes de contratar ${ }^{1}$ submetem seus litígios, relativos a direitos patrimoniais disponíveis, a um ou mais árbitros, sendo estes, em regra, indicados pelas próprias partes. É, das formas de solução alternativa de litígio, a que mais se assemelha ao processo estatal, possuindo procedimento menos burocrático e por isso mais ágil. (LIMA, 2003, p. 35).

Firmada a convenção de arbitragem $^{2}$ em relação a determinado objeto, as partes ficam impedidas de submeter ao Poder Judiciário eventuais conflitos surgidos em virtude da relação firmada, sendo a sentença arbitral impositiva, ou seja, possuindo força de título executivo judicial, conforme dispõe o Código de Processo Civil em seu artigo 515, inciso VII.

No mesmo sentido, dispõe o artigo 31 da Lei n $9.307 / 96$ (também conhecida como Lei Brasileira de Arbitragem):

Art. 31. A sentença arbitral produz, entre as partes e seus sucessores, os mesmos efeitos da sentença proferida pelos órgãos do Poder Judiciário e, sendo condenatória, constitui título executivo. (BRASIL, 1996).

A utilização da arbitragem nos contratos administrativos é tema que vem sendo muito discutido em razão do crescente volume de contratos estabelecidos entre a Administração e o setor privado.

Isto em virtude de que após a Segunda Guerra Mundial o Estado abandonou a condição de gestor dos serviços públicos para se concentrar no desenvolvimento interno. Mais especificamente, nas últimas décadas, os contratos celebrados entre a Administração Pública e particulares tomaram nova força em razão de uma tendência mundial à desestatização, vez que foi constatado que o Estado funciona mais eficientemente quando delega certas funções a particulares especializados na prestação do serviço específico ${ }^{3}$. (LEMES, 2007). Assim, a questão da arbitragem nos contratos da Administração passou a ser foco de discussões, essencialmente, após a entrada em vigor da Lei $\mathrm{n}^{\circ} 11.079 / 2004$, que regula concessões denominadas parcerias público-privadas.

\footnotetext{
${ }^{1}$ Art. $1^{\circ}$ da Lei no 9.307/1996.

2 O termo convenção de arbitragem deve ser entendido tanto como cláusula compromissória, quanto como compromisso arbitral.

${ }^{3} \mathrm{O}$ artigo 173 da atual Constituição Federal ilustra esta tendência.
} 
Recentemente a Lei Brasileira de Arbitragem, alterada pela Lei ${ }^{\circ} 13.129 / 2015$, passou a autorizar expressamente a possibilidade de utilização da Arbitragem pela Administração Pública, o que retirou qualquer dúvida quanto a legalidade da utilização do instituto pelo Estado $^{4}$.

Contudo, ainda que haja dispositivo de Lei autorizativo, é necessário verificar o cabimento e a pertinência da utilização desse meio extrajudicial de controvérsias pelo Estado.

A pesquisa realizada foi elaborada a partir de revisão bibliográfica e pertence à vertente jurídico-teórica por basear-se no conceito, interpretação e aplicação de uma norma jurídica. O raciocínio desenvolvido foi o dedutivo, pois se pretendeu partir do geral para o particular. Por conseguinte, a pesquisa segue o tipo de investigação jurídica exploratória, a partir da análise da lei, com sua decomposição em diversos aspectos.

É nesse sentido que foi realizada a presente pesquisa que buscou verificar se na situação indicada há respeito aos princípios norteadores da administração pública, bem como os impactos econômicos ocorridos em razão da utilização da arbitragem pelo Estado.

\section{ARBITRABILIDADE}

Para análise do tema, faz-se necessário observar e entender a arbitrabilidade referente à Administração Pública.

Arbitrabilidade é um termo existente no direito arbitral que diz respeito à capacidade de matérias e sujeitos serem objeto e partes no procedimento de arbitragem. (SKITNEVSKY, 2008, p. 19).

Segundo Skitnevsky, (2008, p. 21) a arbitrabilidade é considerada por alguns ${ }^{5}$ como os limites impostos à arbitragem ${ }^{6}$ que vedam a utilização deste instituto por determinadas pessoas e sobre determinadas matérias. Outros como Bernard Hanotiau ${ }^{7}$ entendem diferentemente, considerando o termo como a possibilidade de submeter uma disputa à arbitragem. Já

\footnotetext{
${ }^{4}$ Importante destacar que a Administração Pública antes mesmo da alteração da Lei já fazia uso da Arbitragem, com base no entendimento já assentado de autorização, conforme se verificará a seguir.

${ }^{5}$ Como Graig, Park e Paulsson (GRAIG, W. Laurance; PARK, William W.; PAULSSON, Jan. International Chamber of Commerce arbitration. 3rd ed. Oxford University Press, 2000, p. 60 (ICC Publication n. 594) ), citados por Skitnevsky (2008, p.19).

${ }^{6}$ Pela lei interna de cada país.

${ }^{7}$ HANOTIAU, Bernard. Arbitration in Banking and Financial matters. ASA Swiss Arbitration Association Conference in Geneva of January 31, 2003: presentation. Edited by Gabrielle Kaufmann-Kohler and Viviane Frossard. Basel: Association Suisse de L’Arbitrage (ASA), $2003 \quad$ p. 33
} 
Emmanuel Gaillard e John Savage ${ }^{8}$ consideram a arbitrabilidade exclusivamente como a possibilidade de solucionar litígios por arbitragem. (SKITNEVSKY, 2008)

A arbitrabilidade relacionada à capacidade da pessoa figurar como parte no procedimento arbitral é denominada arbitrabilidade subjetiva. Já a arbitrabilidade referente à possibilidade de uma matéria ser submetida à arbitragem é denominada arbitrabilidade objetiva.

Em suma, a arbitrabilidade pode ser considerada como os limites impostos às pessoas e matérias, que as impedem ou permitem serem partes ou objetos no procedimento arbitral. Assim, a arbitrabilidade determina tanto quem e o que pode ser submetido à arbitragem, como quem e o que não o pode, com base na análise da legislação interna de cada país.

Na legislação brasileira, é possível observar o artigo $1^{\circ}$ da Lei $n^{\circ} 9.307 / 96$, o qual dispõe sobre a arbitrabilidade, determinando que "[...] as pessoas capazes de contratar poderão valerse da arbitragem para dirimir litígios relativos a direitos patrimoniais disponíveis." (BRASIL, 1996).

Além disso, conforme mencionado, a recente alteração da Lei Brasileira de Arbitragem, que sofreu diversas modificações por meio da Lei $n^{\circ} 13.129 / 2015$, determinou expressamente a possibilidade do uso da arbitragem pela Administração Pública, dispondo nos parágrafos $1^{\circ} \mathrm{e}$ $2^{\circ}$ do artigo $1^{\circ}$ do referido diploma legal o seguinte:

§ 1o A administração pública direta e indireta poderá utilizar-se da arbitragem para dirimir conflitos relativos a direitos patrimoniais disponíveis.

§ 2 o A autoridade ou o órgão competente da administração pública direta para a celebração de convenção de arbitragem é a mesma para a realização de acordos ou transações. (BRASIL, 1996).

Dessa forma, clara é a possibilidade de utilização da arbitragem pela Administração Pública principalmente após a mudança da Lei Brasileira de Arbitragem que espancou qualquer dúvida acerca do tema.

\subsection{Arbitrabilidade Subjetiva}

A arbitrabilidade subjetiva pode ser entendida como a capacidade de alguém fazer uso da arbitragem como meio alternativo de solução de litígios. A lei pode, em virtude da função ou condição do sujeito, restringir a sua capacidade de ser parte em um procedimento arbitral. (SKITNEVSKY, 2008, p. 27).

8 GAILLARD, Emmanuel; SAVAGE, John. Fouchard Gaillard Goldmanon international commercial arbitration. The Hague; Boston; London: Kluwer Law International, 1999. p. 312 
Esta capacidade subjetiva de utilização da arbitragem é descrita no ordenamento brasileiro na primeira parte do artigo $1^{\circ}$ da Lei $n^{\circ}$ 9.307/96 que dispõe: “As pessoas capazes de contratar poderão valer-se da arbitragem para dirimir litígios [...]”. Assim, é possível extrair que todos aqueles que podem contratar, que são capazes civilmente no ordenamento brasileiro, “pessoas no gozo de seus direitos e obrigações, sejam físicas ou jurídicas, de Direito Privado ou Público" (LEMES, 2007, p.116), também podem fazer uso do instituto da arbitragem.

Segundo Lemes, (2007, p. 117) a relação existente entre a capacidade civil e a capacidade do sujeito em ser parte no procedimento arbitral é recorrente na história do ordenamento brasileiro. Assim, em regra, não existiram na história restrições para utilização da arbitragem pelas pessoas capazes de contratar e isto pode ser observado no Brasil já no ano de 1603 nas Ordenações Filipinas. A única restrição ocorreu no Decreto n 3.900 de 1867 que determinava em seu texto: "podem fazer compromisso todos os que podem transigir", excluindo aqueles que não podem transigir, como por exemplo, a Administração Pública.

Nessa linha de entendimento, ensina Alvim (2007, p. 96):

\footnotetext{
Na arbitragem, pode ser parte tanto a pessoa física quanto jurídica, pública ou privada, desde que a lide envolva "direitos patrimoniais disponíveis". Tanto assim é que o art. $1^{\circ}$ da Lei de Arbitragem fala em "pessoas capazes de contratar" e essa qualidade não é exclusiva de pessoa física. (ALVIM, 2007, p. 96).
}

Dessa maneira, apenas o Caput do artigo $1^{\circ}$ da Lei Brasileira de Arbitragem já seria suficiente para indicar a possibilidade da Administração Pública em figurar como parte em um procedimento arbitral. Contudo, conforme já destacado, o legislador entendeu por necessário indicar expressamente essa autorização por meio da recente alteração ocorrida na Lei Brasileira de Arbitragem, retirando qualquer dúvida sobre o tema.

Desta forma, entende-se que com o atual texto da Lei que as entidades e instituições da Administração Pública, tanto direta como indireta, podem firmar convenção de arbitragem tendo em vista a sua capacidade de contratar, bem como em razão do conteúdo autorizativo do atual texto legal.

\subsection{Arbitrabilidade Objetiva}

A arbitrabilidade objetiva refere-se ao objeto a ser submetido à arbitragem, estabelecendo e limitando as matérias que podem ser submetidas ao procedimento arbitral, sendo uma condição de validade para a cláusula arbitral. (SKITNEVSKY, 2008, p. 25). 
As matérias que podem ser submetidas à arbitragem dizem respeito à disponibilidade do direito na situação específica e dependem da limitação imposta pelo ordenamento ao qual as partes se submetem e à causa em questão. Assim, para saber se a matéria é arbitrável, é necessário buscar as leis específicas a que se refere o caso concreto e analisá-las de forma a verificar se o direito em caso possui impedimentos à utilização da arbitragem, ou seja, se o direito é disponível ou não.

Segundo Skitnevsky (2008, p. 26), de forma geral, os direitos inalienáveis possuem inarbitrabilidade por se tratar de matérias onde existe interesse público ou por serem questões de ordem pública, sendo estas últimas consideradas como o maior dos limites impostos à utilização da arbitragem.

Assim, em suma, o direito pode ser submetido à arbitragem quando for considerado disponível pelo ordenamento, sendo esta uma das condições para validade do compromisso arbitral, tendo em vista que se a matéria não pode ser submetida à arbitragem, será inócua a vontade das partes em utilizar este instituto como forma alternativa de solução de suas controvérsias.

\subsubsection{O interesse público e os bens patrimoniais disponíveis}

Segundo Lemes, (2007, p. 124) o conceito de disponibilidade está intimamente vinculado à definição de negociabilidade e de bens suscetíveis de valor e livres no mercado, ou seja, que tenham patrimonialidade. "Os direitos patrimoniais disponíveis são aqueles direitos que as partes e seus detentores têm a livre disposição, para praticar atos da vida civil, como alienar, vender etc." (LEMES, 2007, p. 124).

Ocorre que na área pública não basta apenas esta análise de possibilidade de negociação e livre disposição do bem, já que o direito também se torna indisponível quando há interesse público primário sobre ele.

O interesse público é termo de difícil e complexa definição, mas pode ser considerado o interesse da coletividade e dos indivíduos que dela fazem parte. Segundo Meirelles, (2003, p. 99) a Lei ${ }^{\circ}$ 9.784/99 dispõe (artigo $2^{\circ}$, parágrafo único, inciso II) sobre interesse público como o "atendimento a fins de interesse geral, vedada a renúncia total ou parcial de poderes ou competência, salvo autorização legal.” (BRASIL, 1999).

O interesse público tem íntima relação com a finalidade e predomina a atuação estatal, "na medida em que a existência do Estado justifica-se pela busca do interesse geral" (MEIRELLES, 2003, p. 99). É importante salientar que "o princípio da supremacia do interesse 
público sobre o privado não é disposto de cima para baixo, mas em mão inversa e objetiva proteger os interesses dos administrados" (LEMES, 2007, p. 126). Assim, não há que se considerar o interesse público como aquele que se opõe aos interesses dos particulares, essa concepção é autoritária e contrária às novas tendências do Direito Administrativo Contemporâneo, conforme ensina Lemes (2007, p. 126).

Freitas do Amaral (2004) classifica de forma restritiva o conceito de interesse público e o define "como sendo o que representa a esfera de necessidades a que a iniciativa privada não pode responder e que são vitais para a comunidade na sua totalidade e para cada um de seus membros". (FREITAS DO AMARAL, 2004, p. 33).

Os interesses públicos podem ser primários ou secundários, conforme a finalidade e influência do interesse coletivo que recaem sobre a matéria em questão.

Os interesses públicos primários são referentes às "atividades-fim" que são desempenhadas pelo Estado para satisfação das necessidades da sociedade e, por serem relativas aos administrados, têm relação com a Administração Pública externa. Estas atividades, por possuírem interesses públicos primários, possuem matérias indisponíveis e, por isso, não podem ser submetidas à arbitragem.

Já os interesses públicos secundários" são relativos às "atividades-meio" desempenhadas pelo Estado e têm como fim operacionalizar os interesses estatais institucionais (referentes a atos, pessoas, serviços etc.), destinando-se, por isso, à satisfação dos interesses públicos secundários ou instrumentais, estando relacionados à Administração Pública interna (MOREIRA NETO, 2001).

\footnotetext{
Os interesses públicos primários são indisponíveis e, por sua vez, os interesses públicos derivados têm natureza instrumental e existem para operacionalizar aqueles com características patrimoniais e, por isso são disponíveis e suscetíveis de apreciação arbitral (LEMES, 2007, p. 131).
}

As “atividades-meio" são executadas em virtude do Estado não possuir acesso a muitos bens e serviços produzidos pelo setor privado, dos quais o setor público necessita. Por esta razão, o Estado acaba por atuar em algumas situações sob o regime de direito privado, com o fim de obter recursos para atender os interesses públicos primários. (LEMES, 2007, p. 132).

É importante também fazer a distinção entre os atos de império e de gestão praticados pelo Estado, considerando-se o interesse público existente em cada um deles.

\footnotetext{
${ }^{9}$ Também denominados de interesses públicos derivados ou instrumentais.
} 
Os atos de império emanam do Poder Político do Estado e não podem ser submetidos à arbitragem. Quando o Estado age como Poder Público ele pratica atos de império e não pode submeter a matéria à arbitragem.

Nas contratações públicas o Estado age como gestor e, apesar de existir a presença de interesse público e da prevalência do Estado em virtude das cláusulas exorbitantes, o interesse nestes casos é secundário. Assim, nestas situações de contratação com o setor privado, o Estado não age como Poder Público, mas tão somente como gestor em sua atividade administrativa. Há, portanto, nesses casos, arbitrabilidade objetiva para a Administração Pública, ou seja, nesta situação ela se torna capaz de utilizar a arbitragem para solucionar eventuais litígios que ocorram em virtude do contrato firmado. (LEMES, 2007).

Lemes (2007, p. 134) cita Eros Roberto $\mathrm{Grau}^{10}$ que sintetiza afirmando que inúmeras vezes o Estado deve dispor de direitos patrimoniais "sem que com isso esteja a dispor do interesse público, porque a realização deste último é alcançada mediante a disposição daqueles" (GRAU apud LEMES 2007, p. 134).

\begin{abstract}
Todavia, quando se trata tão somente de cláusulas pelas quais a Administração está submetida a uma contraprestação financeira, não faz sentido ampliar o conceito de indisponibilidade à obrigação de pagar, vinculada à obra ou serviço executado ou ao benefício auferido pela Administração, em virtude da prestação regular do outro contratante. A convenção de arbitragem será, em tais casos, caminho aberto a que, pelo acordo de vontades, se possa alcançar a plena eficácia da relação contratual. (TÁCITO, 2002, p. 27).
\end{abstract}

Assim, em suma, quando o direito em questão for de interesse público primário ( "atividades-fim” ou atos de império), estará impedida a Administração Pública de submetê-lo à arbitragem. Contudo, quando o interesse público for secundário ("atividades-meio" e atos de gestão) configura-se a arbitrabilidade objetiva da matéria para a Administração Pública.

\title{
3 OS CONTRATOS ADMINISTRATIVOS E A UTILIZAÇÃO DA ARBITRAGEM
}

É de grande importância para este estudo observar o regime jurídico ao qual serão submetidos os contratos administrativos, objetos desta pesquisa. Esta análise se torna fundamental, uma vez que o instituto da arbitragem encontra-se no âmbito do Direito Privado. Dessa forma, para que a Administração Pública possa utilizar a arbitragem como forma de

10 GRAU, Eros Roberto. Da arbitrabilidade de litígios envolvendo sociedades de economia mista e da interpretação da cláusula compromissória. RDBA 18/401, out./dez. 2002. 
solução de litígios, deve haver a possibilidade de aplicação de regras de Direito Privado a estes contratos.

Sobre este assunto, pode-se observar o entendimento de Ferreira Netto (2008, p. 31 -33). Este autor argumenta que a possibilidade de utilização da arbitragem pela Administração, e por isto a capacidade de utilizar princípios de Direito Privado em seus contratos, se deve a uma nova perspectiva participativa atribuída ao Direito Administrativo moderno. Neste sentido, a Administração Pública passou a se aproximar de seus destinatários, havendo uma tendência à redução do autoritarismo estatal. Essa nova perspectiva, também denominada como Administração Pública paritária, visa maior participação dos administrados e maior igualdade entre o Estado e os Particulares, "reforçando a interdependência entre as prestações de ambas as partes." (FERREIRA NETTO, 2008, p. 31).

\begin{abstract}
O caminho da negociação, e não o da imposição, com maior abertura do diálogo sobre as cláusulas que regerão eventual relação jurídica firmada entre Estado e seus administrados, caracteriza uma nova forma de administrar fundada no consenso e em relações jurídicas que aproximam a Administração e particulares, conferindo a ambos tratamento mais isonômico. (FERREIRA NETTO, 2008, p. 32)
\end{abstract}

Nessa perspectiva, é importante observar que, em relação às empresas públicas e às sociedades de economia mista, a disposição do artigo 173, alterado pela Emenda Constitucional 19/98 da Constituição Federal, deixa clara a possibilidade de submissão de seus contratos às regras de direito privado (PALONI, 2006, p. 239 - 240). De acordo com o inciso II do parágrafo $1^{\circ}$ deste artigo, a lei deverá estabelecer regras sobre a sujeição ao regime jurídico próprio das empresas privadas, quanto aos direitos e obrigações civis, quando as empresas públicas e sociedades de economia mista exploram atividade econômica.

\footnotetext{
Art. 173. Ressalvados os casos previstos nesta Constituição, a exploração direta de atividade econômica pelo Estado só será permitida quando necessária aos imperativos da segurança nacional ou a relevante interesse coletivo, conforme definidos em lei.

$\S 1^{\circ}$ A lei estabelecerá o estatuto jurídico da empresa pública, da sociedade de economia mista e de suas subsidiárias que explorem atividade econômica de produção ou comercialização de bens ou de prestação de serviços, dispondo sobre: $[\ldots]$

II - a sujeição ao regime jurídico próprio das empresas privadas, inclusive quanto aos direitos e obrigações civis, comerciais, trabalhistas e tributários; (BRASIL, 1988, grifo nosso).
}

Lemes (2007, p. 50 - 58) também escreve sobre a sujeição dos contratos administrativos às regras de Direito Privado. Segundo a autora, as alterações ocorridas na Constituição Federal a partir da década de 90 tiveram como objetivo impulsionar o desenvolvimento do País e rever 
o papel do Estado na economia. As diversas Emendas Constitucionais ocorridas do ano de 1995 em diante tiveram como finalidade tornar a atividade do Estado centrada no fomento e regulação das atividades realizadas pelo setor privado.

Nesta linha, foram revistos os conceitos e princípios de Direito Administrativo "com o objetivo de democratizar a Administração Pública, com a participação dos cidadãos nos órgãos de deliberação e de consulta e pela colaboração entre ente público e privado na realização das atividades administrativas do Estado" (LEMES, 2007, p. 51). Esta mudança ampliou o processo de privatização e diminuiu o tamanho do Estado permitindo uma atuação mais eficiente da Administração.

Com o aumento da participação privada na execução das atividades Estatais, diversas leis foram alteradas. No âmbito Processual Civil, houve mudanças com o objetivo de estabelecer efetividade na prestação jurisdicional e reduzir as formalidades processuais. Neste contexto também surge a Lei $n^{\circ} 9.307 / 1996$ que regulamenta a arbitragem.

O quadro apresentado teve reflexo em novos paradigmas da Administração Pública. Com efeito, houve impacto nos seus princípios e, por isso, nos contratos administrativos, uma vez que são estes os instrumentos utilizados para que as relações jurídicas entre o setor privado e a Administração Pública sejam estabelecidas.

Como o Estado necessita do setor privado para realizar suas atividades, houve a necessidade de equilibrar a relação estabelecida entre este setor e a Administração, visando maior igualdade entre as partes. Desta forma, "passa-se a dar maior relevo à igualdade de tratamento contratual, tal como no Direito Privado, sem com isso deixar de acatar as cláusulas exorbitantes, peculiares aos contratos administrativos". (LEMES, 2007, p. 53).

Esta mudança de paradigmas tem como objetivo preservar tanto os interesses do contratado (setor privado) quanto do contratante (Administração Pública), sendo o interesse deste último, assegurar aos administrados a satisfação de suas necessidades. A comprovação desta mudança nos paradigmas da administração pode ser observada, como exemplo, com o advento da Lei $\mathrm{n}^{\circ}$ 11.079/2004, que regula as Parcerias Público Privadas. Neste contexto é possível perceber uma flexibilização na legislação infraconstitucional em virtude das reformas Constitucionais ocorridas.

Estas novas formas de conceber a participação privada nos contratos administrativos, a mudança de paradigmas que orientam essas contratações autorizam invocar e acrescentar aos princípios jurídicos administrativos os princípios jurídicos do Direito Privado. Assim, aos contratos administrativos, não obstante terem como norte o interesse público que autorizava invocar as cláusulas excepcionais (cláusulas exorbitantes), tais como o da alteração unilateral do contrato ou sua rescisão, mediante 
equivalente ressarcimento preservando o equilíbrio econômico financeiro do contrato, conforme salientado, também se aplicam os princípios da boa-fé, da lealdade, da confiança legítima, do respeito aos compromissos assumidos etc. (LEMES, 2007, p. 56).

Dessa forma, resta clara a possibilidade de submissão dos contratos administrativos em questão ao regime de Direito Privado, havendo respaldo constitucional para tanto.

\title{
4 OS PRINCÍPIOS DA ADMINISTRAÇÃO FRENTE À UTILIZAÇÃO DA ARBITRAGEM
}

"Princípios são proposições de caráter geral que informam determinado ramo do conhecimento" (GRECO FILHO, 2009, p. 88), obrigando, talvez, de forma mais intensa do que as regras (JUSTEN FILHO, 2006, p. 53).

Para MARÇAL (2007),

\begin{abstract}
Princípio é uma construção teórica integradora, na medida em que é resultado de uma generalização, que reúne e organiza outros e anteriores conhecimentos e, como tal, permite compreender e explicitar a correlação entre conhecimentos e a realidade conhecida. (MARÇAL, 2007, p. 6)
\end{abstract}

Dessa forma, vê-se imprescindível apreciar alguns princípios do direito administrativo frente à utilização da arbitragem para que seja possível verificar o cabimento da utilização deste instituto pela Administração Pública, além do princípio da legalidade já trabalhado em seção anterior. Conforme explicita Lemes (2007, p; 95 - 96) o princípio da legalidade não pode ser interpretado e determinado sozinho, havendo, pela principiologia do Direito, a necessidade de interpretá-lo juntamente com os outros princípios constitucionais. Ademais, a disposição da Lei também necessita estar de acordo com os princípios constitucionais para ser considerada válida em virtude da supremacia da Constituição sobre as demais normas do ordenamento.

Assim, os princípios jurídicos aplicados ao Direito Administrativo, além do princípio da legalidade, que mais se relacionam com a análise da utilização da arbitragem são os seguintes: o princípio da razoabilidade, da proporcionalidade da eficiência e da economicidade.

O princípio da razoabilidade diz respeito, como sua própria denominação remete àquilo que é razoável, "que se situa dentro de limites aceitáveis" (CARVALHO FILHO, 2005, p. 27). Este princípio é aplicado tanto nos contratos administrativos firmados pela administração direta quanto na indireta. É importante ressaltar que a razoabilidade é um juízo de valor, e o que é razoável para um indivíduo pode não ser para outro. Dentro deste quadro, a razoabilidade está atrelada ao princípio da legalidade. Assim, de acordo com esse princípio, a Administração deve 
observar em suas condutas os padrões normais de aceitabilidade, mas a conduta administrativa que estiver inteiramente revestida de licitude não poderá ser considerada violação ao princípio da razoabilidade. (CARVALHO FILHO, 2005, p. 27).

Portanto, como já demonstrado anteriormente, a utilização da arbitragem é considerada compatível com as exigências do princípio da legalidade e, consequentemente, a sua utilização não pode violar o princípio da razoabilidade.

Em relação ao princípio da proporcionalidade, Lemes (2007, p. 155) cita Odete Medauar, que afirma que este princípio determina que quando existem várias medidas apropriadas para um fim, é melhor e conveniente que a Administração utilize a menos gravosa. Em síntese, este princípio determina que a atuação do agente público deve atender ao critério de razoabilidade entre o meio e o fim a ser atingido.

A arbitragem, como se sabe, tem suas causas julgadas de forma mais célere do que as submetidas ao Poder Judiciário. Ademais, é mais econômica e técnica e, por isso, mais vantajosa em muitos casos. Desta forma, em razão destes benefícios, a utilização deste instituto está em consonância com o princípio da proporcionalidade. (LEMES, 2007, p. 157).

Já o princípio da eficiência, introduzido no artigo 37 da Constituição Federal pela Emenda Constitucional $n^{\circ}$ 19/98, diz respeito ao dever de otimização dos recursos públicos. Este princípio impõe como primeiro dever da Administração evitar o desperdício e a falha (JUSTEN FILHO, 2006, p. 86). “Com a inclusão, pretendeu o Governo conferir direitos aos usuários dos diversos serviços prestados pela Administração ou por seus delegados e estabelecer obrigações efetivas aos prestadores” (CARVALHO FILHO, 2005, p. 21). Para Meirelles (2003, p. 94) o princípio da eficiência é o princípio mais moderno da função administrativa “[...] que já não se contenta em ser desempenhada apenas com legalidade, exigindo resultados positivos para o serviço público e satisfatório atendimento das necessidades da comunidade e de seus membros" (MEIRELLES, 2003, p. 94).

Dentro do que se entende pelo princípio da eficiência, existe o princípio da economicidade que, segundo Lemes (2007, p. 154), determina a busca pela Administração de melhor custo/benefício na realização de despesas ou de obtenção de receita pública. ${ }^{11}$

A utilização da arbitragem corrobora completamente com o fim procurado pelo legislador ao inserir o princípio da eficiência na Constituição Federal. Isto pelo fato de que a

${ }^{11}$ É importante lembrar que segundo JUSTEN FILHO (2006, p. 86) a eficiência administrativa não é sinônimo de eficiência econômica, não é a busca pela obtenção de maior lucro, mas a busca pela realização de seus fins pelos meios de menor custo econômico possível. Ao contrário, quando a Administração Pública desempenha atividade econômica propriamente dita (como no caso das instituições bancárias) há uma busca direta pela eficiência econômica, tendo em vista que neste caso há a busca do lucro, como qualquer empresa do setor privado. 
arbitragem é um meio mais célere e eficaz de solução de litígios. Em um caso hipotético de uma obra pública, o surgimento de um litígio que acarrete na suspensão da construção, depende a sociedade da solução mais rápida e eficaz do litígio para que obtenha os resultados advindos daquela obra. Ademais, a arbitragem evita o desperdício de tempo e, em muitos casos, de dinheiro público, sendo mais vantajosa e benéfica a utilização da arbitragem que trará a Administração mais rapidamente à satisfação das necessidades dos administrados.

Por fim, em relação ao princípio da legalidade o artigo 37 da Constituição Federal dispõe sobre o princípio da legalidade administrativa e determina que a Administração Pública só pode agir em virtude de autorização/determinação legal, diferentemente do que ocorre com o particular que, em virtude do princípio da legalidade disposto no artigo $5^{\circ}$ da Constituição Federal, pode fazer ou deixar de fazer o que quiser desde que a lei não proíba. Assim, o administrador público depende da determinação legal para validade e eficácia de suas ações, não podendo se desviar do que dispõe o ordenamento.

O princípio da legalidade é certamente a diretriz básica da consulta dos agentes da Administração. Significa que toda e qualquer atividade administrativa deve ser autorizada por lei. Não o sendo, a atividade é ilícita. (CARVALHO FILHO, 2005, p. 16)

O silêncio da lei não interessa à Administração Pública. Assim, para que o Estado possa utilizar a arbitragem como meio alternativo de solução de litígios é necessário que a lei determine esta possibilidade.

O artigo $1^{\circ}$ da Lei $n^{\circ}$ 9.307/96, especialmente após a alteração do referido diploma legal em 2015, é o dispositivo de lei que autoriza a utilização da arbitragem pela Administração, havendo, portanto, legalidade em sua utilização pelo Estado.

\section{REPERCUSSÕES ECONÔMICO-FINANCEIRAS DA UTILIZAÇÃo DA ARBITRAGEM}

Buscando-se entender o impacto da economia no direito e do direito na economia, em virtude de ter sido evidenciado que esta relação existia, buscou-se entendê-la e verificar como ela se dava. (LEMES, 2007).

A análise da influência das instituições jurídicas na economia passou a ser estudada a partir da década de 60 nos Estados Unidos pela matéria interdisciplinar denominada "Direito e Economia" sendo este um movimento tido por muitos como o "de maior impacto na literatura 
jurídica da segunda metade do século passado" (SALAMA, 2008, p. 03). Esta "disciplina serve, antes de tudo, para iluminar problemas jurídicos e para apontar implicações das diversas possíveis escolhas normativas". (SALAMA, 2008, p. 02).

Neste contexto os contratos são especialmente considerados tendo em vista que, por um lado, são instrumentos jurídicos, já que regulam direitos e obrigações entre as partes que o celebram e, por outro, são instrumentos econômicos, por terem como foco a circulação de riquezas. (LEMES, 2007, p. 159). Isto porque, segundo Décio Zylbersztajn e Raquel Sztajn ${ }^{12}$, citados por Lemes (2007, p. 159), as instituições legais têm impacto no comportamento dos agentes econômicos. Esse impacto se dá em virtude dos custos de transação ${ }^{13}$ terem relação direta com as instituições e formas organizacionais do ambiente social (COASE apud LEMES, 2007, p. 159)

Dessa forma, tudo que se relaciona com contratos passa a ser economicamente relevante, incluindo-se aí o surgimento e solução dos conflitos que eventualmente se formam em virtude de uma relação contratual, e, nessa perspectiva, pode-se afirmar que o direito devese pautar de acordo com os fins econômicos que atingem a sociedade de forma direta, já que o bom andamento econômico reflete positivamente na vida dos indivíduos.

Segundo a Teoria dos Custos da Transação, é possível prever em um contrato os seus possíveis problemas futuros. Ocorre que, devido à racionalidade limitada dos seres humanos, alguns possíveis obstáculos não podem ser previstos logo no momento da elaboração contratual, existindo, inevitavelmente, lacunas no instrumento. Assim, os agentes ${ }^{14}$ oportunistas são estimulados, em virtude da existência de lacunas, a não adimplir o contrato. (ZYLBERSZTAJN \& SZTAJN apud LEMES, 2007). Desta forma, é necessário que existam leis eficientes e adequadas para o preenchimento dessas lacunas, bem como um julgamento adequado e célere de possíveis conflitos para que os oportunistas entendam ser desvantajoso o descumprimento do contrato, uma vez que serão responsabilizados de forma rápida e eficiente por seu ato de máfé, não sendo interessante o inadimplemento das obrigações firmadas. (LEMES, 2007, p.162 163).

Quando é verificado que poderão existir custos para que uma determinada transação se concretize $^{15}$ (como por exemplo, a existência de um corpo de leis ineficientes ou julgamento

\footnotetext{
12 ZYLBERSZTAJN, Décio; SZTAJN, Raquel. Análise econômica do direito e das organizações. In: Direito \& Economia, ZYLBERSZTAJN, Décio; SZTAJN, Raquel (orgs.) Rio de Janeiro: Elsevier, 2005, p.2.

${ }^{13}$ Segundo KUPFER (2002) os custos de transação são os gastos que os agentes econômicos enfrentam todas as vezes que recorrem ao mercado, ou seja, são custos de negociar, redigir e garantir o cumprimento dos contratos.

${ }^{14}$ Contratante ou contratado.

${ }^{15}$ Os custos sempre existirão, mas podem ser muito grandes em comparação com outro ambiente.
} 
inadequado e moroso de uma eventual desavença) há impacto economicamente negativo na forma como as empresas se comportarão na estrutura e hierarquia da organização e na forma como as atividades econômicas serão desenvolvidas. Isto em virtude de que todas as possíveis dificuldades observadas pelas empresas, incluindo obstáculos relativos ao adimplemento das obrigações, norteiam as decisões das empresas, podendo fazer com que elas evitem o mercado e recorram a outras opções. (CAMARGO CONCEIÇÃO, 2001, p. 113 - 114).

Oliver Williamson, citado por Lemes (2007, p. 166) entende que, para que sejam minimizados os custos de transação, devem ser trabalhadas as possibilidades de descumprimento dos contratos, já que todos os contratos de grande complexidade são inevitavelmente incompletos.

Mais especificamente, em relação à Administração Pública, importa verificar que a partir dos anos 80, em razão de uma tendência mundial de desestatização e privatização das atividades estatais, os particulares passaram a exercer algumas tarefas que até então só eram exercidas pelo Estado (LEMES, 2007, p.160 - 161). Por esta razão o Estado passou a celebrar contratos com os particulares de modo frequente e necessário à satisfação das necessidades sociais.

Assim, é relevante para esta pesquisa analisar, sobre o prisma do Direito e Economia, as implicações e influências econômicas advindas dos contratos celebrados pela Administração Pública com os particulares para que seja possível verificar se a utilização do instituto da arbitragem nestas relações tem impacto positivo na economia.

A Administração Pública, precipuamente, deve buscar a satisfação das necessidades dos administrados. Desta maneira, é papel da Administração buscar, entre outros objetivos, o equilíbrio e o desenvolvimento econômico que trazem benefícios sociais. Como apresentado, a eficiência das leis e um julgamento célere e adequado traz à sociedade benefícios econômicos, reduzindo os custos de transação e favorecendo os agentes em suas transações e dando a estas estabilidade.

De acordo com Salama (2008):

Em países em desenvolvimento como o Brasil o emprego eficiente dos recursos existentes deve ser uma prioridade nacional. Para enfrentar seus problemas, a sociedade brasileira necessita de instrumentos jurídicos eficientes que estimulem as atividades produtivas, a resolução de conflitos de forma pacífica, a democracia, a livre iniciativa, a inovação, e a redução da corrupção e da burocracia, do desperdício e da pobreza. O estudo dos incentivos postos pelos institutos jurídicos faz parte deste esforço, e os estudiosos do Direito podem e devem tomar parte neste processo.
(SALAMA,
2008 ,
p.

02) 
É neste contexto que a arbitragem se insere, uma vez que se trata de meio extrajudicial de solução de conflitos que é meio célere de resolução de demandas. Além disso, a arbitragem dá à causa possibilidades muito maiores de um julgamento adequado, vez que o árbitro pode ser escolhido pelas partes por seu conhecimento específico relacionado à especialidade da disputa.

[...] podemos enumerar, entre as inúmeras vantagens da arbitragem em relação a Justiça Comum, as seguintes: rapidez e simplicidade, por ser seu procedimento menos formal; menor desgaste e ansiedade; relação custo e benefício mais atraente, principalmente para questões envolvendo grandes somas; atendimento aos requisitos de neutralidade, confiabilidade e imparcialidade dos árbitros; maior autonomia das partes; natureza da sentença arbitral idêntica a da decisão judicial; sigilo ${ }^{16}$; melhor qualidade da decisão, já que pode nomear um especialista na matéria como árbitro; por ser um procedimento consensual, cria-se uma atmosfera favorável à mútua cooperação das partes; maior aderência das partes à sentença arbitral, já que proferida por um árbitro de confiança das próprias partes; não é um procedimento litigioso, como a demanda judicial; as audiências podem ser marcadas em horários e locais que melhor convierem às partes. (LIMA, 2003, p.41 - 42).

Assim, a utilização da arbitragem tem impacto positivo na economia, reduzindo os custos de transação, pois a inserção da cláusula arbitral no contrato desestimula o oportunismo tendo em vista que o agente sabe que o julgamento da causa será célere e eficiente, havendo a responsabilização necessária e eficaz para qualquer ato oportunista e de má-fé das partes. Assim,

O agente privado podendo prever que o contrato administrativo disporá sobre a forma extrajudicial de solução de conflitos por arbitragem, tal como regulada na Lei $\mathrm{n}^{\circ}$ 9.307/96, e ciente que este processo é mais célere e especializado (considerando os aspectos técnicos do contrato) do que o Judiciário levará em consideração este fator refletido nos custos de transação e ofertará preço menor. (LEMES, 2007, p. 169).

Dessa maneira, e principalmente considerando a redução do preço a ser pago pela Administração Pública por um bem ou serviço ao seu parceiro privado, verifica-se vantajosa a opção pela utilização da Arbitragem pelo Estado o que, em última análise, beneficia diretamente aos administrados, considerando que a Administração empregará seus recursos de forma econômica, possibilitando que outros ou maiores investimentos sejam feitos com o valor economizado.

\footnotetext{
${ }^{16}$ Nas causas que envolvem o Poder Público será necessário que o procedimento arbitral seja público, em virtude do princípio da publicidade dos atos administrativos.
} 


\section{CONCLUSÃO}

Pela presente pesquisa, ficou constatado que a utilização do instituto da arbitragem, como meio de solução de litígios, pode oferecer vantagens ao Estado.

Como verificado, a Lei ${ }^{\circ}$ 9.307/1996 traz consigo a arbitrabilidade objetiva do Estado a partir do momento em que determina que podem fazer uso da arbitragem aqueles que podem contratar, bem como em razão da recente alteração do texto legal que incluiu em seus parágrafos $1^{\circ}$ e $2^{\circ}$ a possibilidade da utilização do referido instituto pela Administração. A arbitrabilidade subjetiva surge à Administração quando o direito possui interesse público secundário, ou seja, quando o direito possui patrimonialidade, podendo o Estado, nos atos de gestão, utilizar este meio de solução de controvérsias.

Nas últimas décadas a arbitragem ganhou nova força no âmbito administrativo em virtude dos novos rumos empreendidos pela Administração Pública que determinaram uma maior busca por eficiência na satisfação das necessidades dos administrados. Ademais, o Estado percebeu que trabalha melhor quando delega funções a terceiros especializados.

Foi possível perceber que há respaldo constitucional para submissão dos contratos administrativos às regras de Direito Privado, não sendo vedada, por isto, a utilização da arbitragem pela Administração Pública. Chega-se a esta conclusão em virtude da observância das várias reformas constitucionais ocorridas na década de 1990, as quais fizeram com que a Administração passasse a primar pela eficiência e a buscar no setor privado uma parceria imprescindível à devida e eficiente consecução das atividades Estatais.

Em relação aos princípios administrativos, ficou claro que não há afronta a estes, muito pelo contrário, a sua utilização corrobora com o princípio da eficiência e da economicidade, e está de acordo com o princípio da razoabilidade. Quanto ao princípio da legalidade, este é respeitado, considerando a existência de dispositivo legal autorizativo (artigo $1^{\circ}$ da Lei $n^{o}$ 9.307/96).

Analisando os aspectos econômicos da utilização do instituto pela Administração, foi possível verificar que existem benefícios para a Economia em sua utilização, vez que a sua estipulação desestimula a ação de oportunistas, considerando que os agentes preferem implementar suas obrigações a descumpri-las e serem responsabilizados por seus atos de má-fé de forma célere e eficiente. Por consequência, os custos de transação são reduzidos, estimulando as empresas a firmarem contratos com a Administração, bem como recorrerem ao mercado para consecução de suas atividades. 
A arbitragem é meio de solução de conflitos célere, especializado e econômico e, portanto, oferece aos administrados menores prejuízos em virtude de eventuais conflitos surgidos em relações contratuais firmadas entre Estado e particulares com o objetivo de satisfazer as necessidades dos administrados.

Em conclusão, a interpretação da norma no sentido de que a Administração pode fazer uso da arbitragem, coloca o Estado em uma situação favorável e estimulante à economia, permitindo que os objetivos da Administração sejam alcançados de forma mais adequada aos seus interesses.

\section{REFERÊNCIAS}

ALVIM, J.E. Carreira. Direito Arbitral. 3 ed. Rio de Janeiro: Forense, 2007.

BRASIL. Constituição (1988) Constituição da República Federativa do Brasil. Brasília: Senado, 1988. 168p.

BRASIL. Lei $\underline{n}^{0}$ 9.307, de 23 set 1996. Dispõe sobre a arbitragem. Diário Oficial da União, Brasília, 24 set 1996.

BRASIL. Lei $\underline{n}^{0}$ 9.784, de 29 jan 1999. Regula o processo administrativo no âmbito da Administração Pública Federal. Diário Oficial da União, Brasília, $1^{\circ}$ fev 1999.

BRASIL. Lei $\underline{n}^{0} 11.079$, de 30 de dez 2004. Institui normas gerais para licitação e contratação de parceria público-privada no âmbito da administração pública. Diário Oficial da União, Brasília, 31 dez 2004.

CAMARGO CONCEIÇÃO, Octávio Augusto. Instituições, crescimento e mudanças na ótica institucionalista. 2001, 228f. Tese (doutorado). Fundação de Estatística Siegfried Emanuel Heuser. Porto Alegre.

CARVALHO FILHO, José dos Santos. Manual de Direito Administrativo. 14 ed. Rio de Janeiro: Lumen Juris, 2005.

FERREIRA NETTO, Cássio Teles. Contratos administrativos e arbitragem. 1 ed. Rio de Janeiro: Elsevier, 2008.

FREITAS DO AMARAL, Diogo. Curso de Direito Administrativo. $3^{\text {a }}$ reimpressão. Lisboa: Almedina, vol. II, 2004.

GRECO FILHO, Vicente. Direito Processual Civil Brasileiro. 20 ed. São Paulo: Saraiva, 2009. v. 2.

JUSTEN FILHO, Marçal. Curso de Direito Administrativo. 2 ed. São Paulo: Saraiva, 2006. 
LEMES, Selma M. Ferreira. A arbitragem e os novos rumos empreendidos na administração pública: a empresa estatal, o Estado e a concessão de serviço público. In: Aspectos fundamentais da lei de arbitragem / Pedro A. Batista Martins, Selma M. Ferreira Lemes, Carlos Alberto Carmona. - Rio de Janeiro: Forense, 1999, p. 175-206.

LEMES, Selma M. Ferreira. Arbitragem na Administração Pública: Fundamentos Jurídicos e Eficiência Econômica 1 ed. São Paulo: Quartier Latin do Brasil, 2007.

LIMA, Leandro Rigueira Rennó. Arbitragem: uma análise da fase pré-arbitral. 1 ed. Belo Horizonte: Mandamentos, 2003.

MEIRELLES, Hely Lopes. Direito Administrativo Brasileiro. 28 ed. São Paulo: Malheiros, 2003.

MOREIRA NETO, Diogo de Figueiredo. Curso de Direito Administrativo. 12 ed. Rio de Janeiro: Forense, 2001.

MARÇAL, Antônio Cota. Princípio: Estatuto, função e usos no direito. In: TAVARES, F. Horta (org.). Constituição, Direito e Processo. Curitiba: Juruá, 2007, p. 31-58.

PALONI, Nelson Alexandre. A utilização da arbitragem por instituições financeiras públicas. Revista do BNDES, Rio de Janeiro, vol. 13, n. 26, p. 237-260, dez.. 2006.

Disponívelem: $<$ http://www.bndes.gov.br/SiteBNDES/export/sites/default/bndes_pt/Gale rias/Arquivos/conhecimento/revista/rev2611.pdf>. Acesso em: 23 mai. 2011.

SALAMA, Bruno Meyerhof. O que é "Direito e Economia"?. In: TIMM, Luciano Benetti (Org.). Direito \& Economia. 2 ed. (rev. e atual.). Porto Alegre: Livraria do Advogado, 2008.

SKITNEVSKY, Karin Hlavnicka. Arbitrabilidade nos contratos com a Administração Pública. 2008, 123f. Tese (mestrado). Pontifícia Universidade Católica de São Paulo. São Paulo.

TÁCITO, Caio. O juízo arbitral em direito administrativo. In: Reflexões sobre arbitragem: in memoriam do Desembargador Cláudio Vianna de Lima / coordenadores Pedro A. Batista Martins, José Maria Rossani Garcez. - São Paulo: LTr, 2002, p. 23-28.

ZYLBERSZTAJN, Décio; SZTAJN, Raquel. Análise econômica do direito e das organizações. In: ZYLBERSZTAJN, Décio; SZTAJN, Raquel (orgs.). Direito \& Economia. Rio de Janeiro: Elsevier, 2005, p. 1 - 15. 